\title{
A New Approach for Wage Management System Using Fuzzy Brackets in Industry
}

\author{
Ergün Eraslan' and Kumru Didem Atalay ${ }^{2}$ \\ ${ }^{1}$ Department of Industrial Engineering, Yıldırım Beyazıt University, Çiçek Sokak No. 3, Ulus, 06050 Ankara, Turkey \\ ${ }^{2}$ Department of Medical Education, Baskent University, Bahcelievler, 06490 Ankara, Turkey \\ Correspondence should be addressed to Ergün Eraslan; erguneraslan@gmail.com
}

Received 25 April 2013; Accepted 23 September 2013

Academic Editor: Yuri Vladimirovich Mikhlin

Copyright (c) 2013 E. Eraslan and K. D. Atalay. This is an open access article distributed under the Creative Commons Attribution License, which permits unrestricted use, distribution, and reproduction in any medium, provided the original work is properly cited.

\begin{abstract}
Job evaluation is used to determine the relative importance of each job in a company in order to structure an accurate wage management system. Job evaluation can be also defined as a multicriteria decision-making problem. However, according to the diversity of managers' assessment, the evaluation processes are often resulting in pay inequity. This outcome can be circumvented by utilizing a fuzzy job evaluation system. In this study, one of the more robust multicriteria decision-making methods, Fuzzy Analytic Hierarchy Process (FAHP), is performed in job evaluation system in order to rank predetermined 13 criteria. The fuzzy wage brackets are developed and inserted into the process which is obtained from the results of mathematical model to designate the bounds for predefined 86 jobs. Eventually an accurate payment system is proposed for a company in steel industry by using Fuzzy Regression Analysis (FRA).
\end{abstract}

\section{Introduction}

Job evaluation is one of the most important functions of Human Resources Management and a systematic technique that enables the design, establishment, and improvement of human resources [1]. These processes include establishing a payment system and managing personnel contracts and agreements related to their jobs. In an organizational structure, different kinds of jobs exist and each differs in their specifications and contributions to the company. The worth of each job has to differ from one to another in respect of these features. The subject of job evaluation consists of this relative worth determination [2].

A job evaluation system is comprised of two major issues: (1) evaluation of the job specification and (2) equal pay for equal work. These issues provide the labor productivity, job royalty, and job satisfaction for employees. It is also functional for the managers in order to do select appropriate personnel, to create the division of the labor and organizations, to secure the occupational health and safety, and so forth.

There are a few job evaluation techniques in the literature. The techniques are divided into two categories. One of them is nonanalytical techniques which are the Sequencing Method and the Classification Method. These techniques are performed when there are few numbers of jobs to be evaluated, for the easiness of the application and in the development phase of works. To avoid the subjective assessment in the companies where there are a large number of workers, the analytical methods should be preferred which are the Factor Comparison Method and the Point Method [3].

The methods used in the job evaluation include ranking, classification, factor comparison, job components, and point system [4]. The well-known and maybe the most reliable method is the Point Method. This method is widely used in different areas because it achieves more accurate results [5]. In this method, used in this study, jobs are rated on a set of factors and the total scores are calculated for all the jobs [6]. In the wage brackets, the seniority, success, and some social expenses are included to designate the real payment system [3]. The Point Method follows some steps below [7]:

(i) construction of the expert evaluation group,

(ii) preparation of the work plan and coverage,

(iii) preliminary designs, 
(iv) educational studies,

(v) work analysis,

(vi) determination of the point plan table,

(vii) calculation of the factor values.

Some researchers have considered the pay inequity as being the most important term of job evaluation, that is, equal pay for equal work [8]. Smith et al. [9] put forth a critique about the effects of job description content on the job evaluation judgments. In the studies over recent decades, Spyridakos et al. [1] studied the multicriteria job evaluation for large organizations, and Das and Garcia-Diaz [7] proposed a computerized statistical procedure in factor selection guidelines for the job evaluation. Gupta and Ahmed [10] and Dağdeviren et al. [11] used a goal programming approach and Xing et al. [5] used the Analytic Hierarchy Process (AHP) evaluation for the problem of factor weights determination. Therefore game theory is the traditional solution to the many problems (Perc et al.) [12, 13].

The job evaluation could be defined as a managerial decision-making problem with its multiple objectives [14]. Scoring these objectives is a difficult task for the decision makers because many different scores can emerge within a group of managers. Therefore, the decision-making process should be considered as a fuzzy process in naturally. With a fuzzy approach, varying opinions of the managers could be considered in the evaluation system. Thereby, the subjectivity of the decision makers could be prevented.

The fuzzy theory allows both mathematical operators and fuzzy programming to apply the fuzzy domain. Fuzzy set is a class of objects which uses a membership (characteristic) function and it assigns a grade of membership ranging between zero-one to each object. There are many ranking methods developed in the literature for the fuzzy numbers. These methods may generate different ranking results and most of them require complex mathematical calculations [15].

In this study, the fuzzy AHP method (FAHP), that is more appropriate due to its nature of fuzziness, was used for the job evaluation systems [16]. During the evaluation processes of each job, fuzziness was obtained by using the fuzzy pairwise comparisons in the judgment matrices. Hence, more accurate weights could be obtained in order to use for factor scoring. To improve the model, the fuzzy wage brackets are considered and embedded into the decision process with the result of mathematical model which sets the upper and lower bounds. Then by using Fuzzy Regression Analysis (FRA), an accurate payment system is proposed for the first time for a steel company.

\section{The Techniques Used in This Study: FAHP and FRA}

The FAHP is a provided systematic approache to the alternative selection and justification problem by using the concepts of fuzzy set theory and hierarchical structure analysis. Decision makers are usually more confident in giving interval judgments rather than crisp judgments due to the fuzzy nature of the comparison process.
The earliest work in FAHP appeared in Van Laarhoven and Pedrycz [17], which compared fuzzy ratios described by triangular membership functions. Buckley [18] determined fuzzy priorities of comparison ratios whose membership functions were trapezoidal. Chang [19] introduced a new approach for handling FAHP, with the use of triangular fuzzy numbers for pairwise comparison scale of FAHP and the use of the extent analysis method for the synthetic extent values of pairwise comparisons. The outcome of Cheng's algorithm [20] can finally be defuzzified by forming the surface centre of gravity of any fuzzy set. Kahraman et al. [21-23] used a fuzzy objective and subjective method obtaining the weights from AHP and producing a fuzzy weighted evaluation. Recently, Büyüközkan et al. [24], Tolga et al. [25], and Kulak and Kahraman [26] applied the same approach to some selection problems. In this study, FAHP method is used to calculate local weights using detailed information about Chang et al's $[27,28]$ extent analysis (see the appendix).

FRA was first introduced by Tanaka et al. in 1982 [29]. In their study, a regression problem with fuzzy output and crisp input was formulated as a mathematical programming problem. The objective was to minimize the total spreads of the fuzzy parameters subject to the constraint that the regression model needed to satisfy a prespecified membership value in estimating the fuzzy outputs. Different researchers used Tanaka's approach to minimize the total spread of the output [30, 31]. Sakawa and Yano [32], Kim and Bishu [33], and Peters [31] considered the possibility and necessity conditions for fuzzy equality. Tanaka and Lee [34] proposed an interval regression analysis based on quadratic programming approach. Azadeh et al. [35] applied FRA for energy forecasting problems. Tseng and $\mathrm{Hu}$ [36] proposed a quadratic-interval Bass model that combines quadraticinterval regression with the Bass innovation diffusion model to solve a fuzzy relationship between explanatory and output variables and to provide forecasts of sales to decision makers.

Fuzzy regression models have been successfully applied to various engineering and technological problems [30, 3742]. It can also be applied for the estimation of the fuzzy job evaluation process in the manufacturing companies. Additionally, instead of the crisp values of wage brackets, obtaining a fuzzy interval is more relevant to the real life problems which are why the linguistic variables are used commonly. FRA has been shown to be more flexible and rigorous than the traditional (nonfuzzy) approach $[43,44]$.

The aim of regression analysis is to find an appropriate mathematical model and to determine the best fitting coefficients of the model from the given data. This classical regression technique is useful in a nonfuzzy environment where the relationship among variables is crisply defined. However, it is very difficult to obtain an exact relation. The use of statistical regression is restricted by some strict assumptions and statistical properties about the given data. Fuzzy regression does not require normal distributed data, stability tests, and large samples. It can be applied to many real life problems in which the strict assumptions of statistical regression analysis cannot be met. FRA considers the use of fuzzy numbers that involves the modeling of problems where the output variable is affected by imprecision. The goal of FRA 
is to find a regression model that fits all observed fuzzy data within a specified fitting criterion.

The basic model that is developed by Tanaka et al. [29] model assumes a fuzzy linear regression function as

$$
\widetilde{Y}_{i}=\widetilde{A}_{0} X_{0}+\widetilde{A}_{1} X_{1}+\widetilde{A}_{2} X_{2}+\cdots+\widetilde{A}_{n} X_{n}=A X
$$

where $X=\left[X_{0}, X_{1}, \ldots, X_{n}\right]^{T}$ is an input vector. $\widetilde{A}=$ $\left[\widetilde{A}_{0}, \widetilde{A}_{1}, \ldots, \widetilde{A}_{n}\right]$ is a vector of fuzzy coefficients in the form of symmetric triangular fuzzy number denoted by $\widetilde{A}_{j}=\left(\alpha_{j}, c_{j}\right)$, where $\alpha_{j}$ is its central value and $c_{j}$ is the spread value and $c_{j} \geq 0$. Therefore (1) can be rewritten as

$$
\tilde{Y}_{i}=\left(\alpha_{0}, c_{0}\right) X_{0}+\left(\alpha_{1}, c_{1}\right) X_{1}+\cdots+\left(\alpha_{n}, c_{n}\right) X_{n}
$$

The estimated output $\tilde{Y}_{i}$ can be obtained by using the extension principle [45]. The derived membership function of fuzzy number $\widetilde{Y}_{i}$ can be stated as

$$
\mu_{\widetilde{Y}_{i}}\left(y_{i}\right)= \begin{cases}1-\frac{\left|Y_{i}-X^{T} \alpha\right|}{c^{T}|X|}, & X \neq 0, \\ 1, & X=0, Y_{i}=0, \\ 0, & X=0, Y_{i} \neq 0,\end{cases}
$$

where $c^{T}=\left(c_{0}, c_{1}, \ldots, c_{n}\right)$ and $\alpha=\left(\alpha_{0}, \alpha_{1}, \ldots, \alpha_{n}\right)$. The above FRA assumes that input and output data are crisp, while the relation between the input and output data is defined by fuzzy function of which the distribution of the parameter is a possibility function [46].

To determine the optimal fuzzy coefficients $\widetilde{A}_{j}=\left(\alpha_{j}, c_{j}\right)$ of the fuzzy regression model (2), the sum of spreads of the estimated outputs was used as an objective function in linear programming (LP) problems $[29,46]$ that has an objective function as

$$
\begin{gathered}
\min J=c^{T}|X|, \\
\min J=\sum_{j=1}^{n}\left(c_{j} \sum_{i=1}^{m}\left|x_{i j}\right|\right),
\end{gathered}
$$

where the $m$ collected input data are defined as $x_{i j}(i=$ $1, \ldots, m, j=1, \ldots, n)$ of $n$ independent variables. This approach is called the LP approach in fuzzy regression analysis. The objective function given in (4) is to minimize the total spread of the fuzzy number $\widetilde{Y}_{i}$. The constraints require that each observation $Y_{i}$ has at least $h$ degree of belonging to $\tilde{Y}_{i}$ as $\mu_{\widetilde{Y}_{i}}\left(y_{i}\right) \geq h(i=1, \ldots, m)$, which is equivalent to

$$
1-\frac{\left|Y_{i}-X^{T} \alpha\right|}{c^{T}|X|} \geq h, \quad \forall i=1,2, \ldots, m
$$

The above analysis leads to the following LP problem [29]:

$$
\begin{gathered}
\min J=\sum_{j=1}^{n}\left(c_{j} \sum_{i=1}^{m}\left|x_{i j}\right|\right), \\
\sum_{j=0}^{n} \alpha_{j} x_{i j}+(1-h) \sum_{j=0}^{n} c_{j}\left|x_{i j}\right| \geq y_{i}, \quad i=1, \ldots, m, \\
\sum_{j=0}^{n} \alpha_{j} x_{i j}-(1-h) \sum_{j=0}^{n} c_{j}\left|x_{i j}\right| \leq y_{i}, \quad i=1, \ldots, m, \\
c_{j} \geq 0, \quad j=0, \ldots, n, \quad 0 \leq h \leq 1 .
\end{gathered}
$$

\section{A Proposed Job Evaluation Model with Fuzzy Wage Brackets: An Experimental Study}

In this section, a new job evaluation model is proposed for steel industry and its steps are identified. The usability of the proposed fuzzy model was tested in a steel manufacturing company. For the application, a decision committee was established comprised of seven service managers and numerous responsible chiefs of the company each from different departments. The proposed job evaluation system for steel industry using FAHP method follows the steps of Figure 1.

Step 1 (identifying the factors and subfactors to be used in the model). It was decided to use the factors and subfactors outlined by the Turkish Trade Union of Metal Industrialists with some revisions consistent with the related steel company's structure. A total of 13 subfactors are given below organized into 4 areas: mastery, responsibility, workload, and physical and working conditions.

Mastery factors (MF):

(i) education and basic knowledge (EK),

(ii) experience (EX),

(iii) skill (SK),

(iv) predisposition (PD).

Responsibility factors (RF):

(i) machine/equipment responsibility (MR),

(ii) material/product responsibility (PR),

(iii) production continuity responsibility (CR),

(iv) security providing responsibility (SR).

Workload factors (WF):

(i) mental effort (ME),

(ii) physical effort (PE).

Physical and working conditions factors (PF):

(i) job risks (JR),

(ii) working environment (WE),

(iii) protective material necessity (PN). 

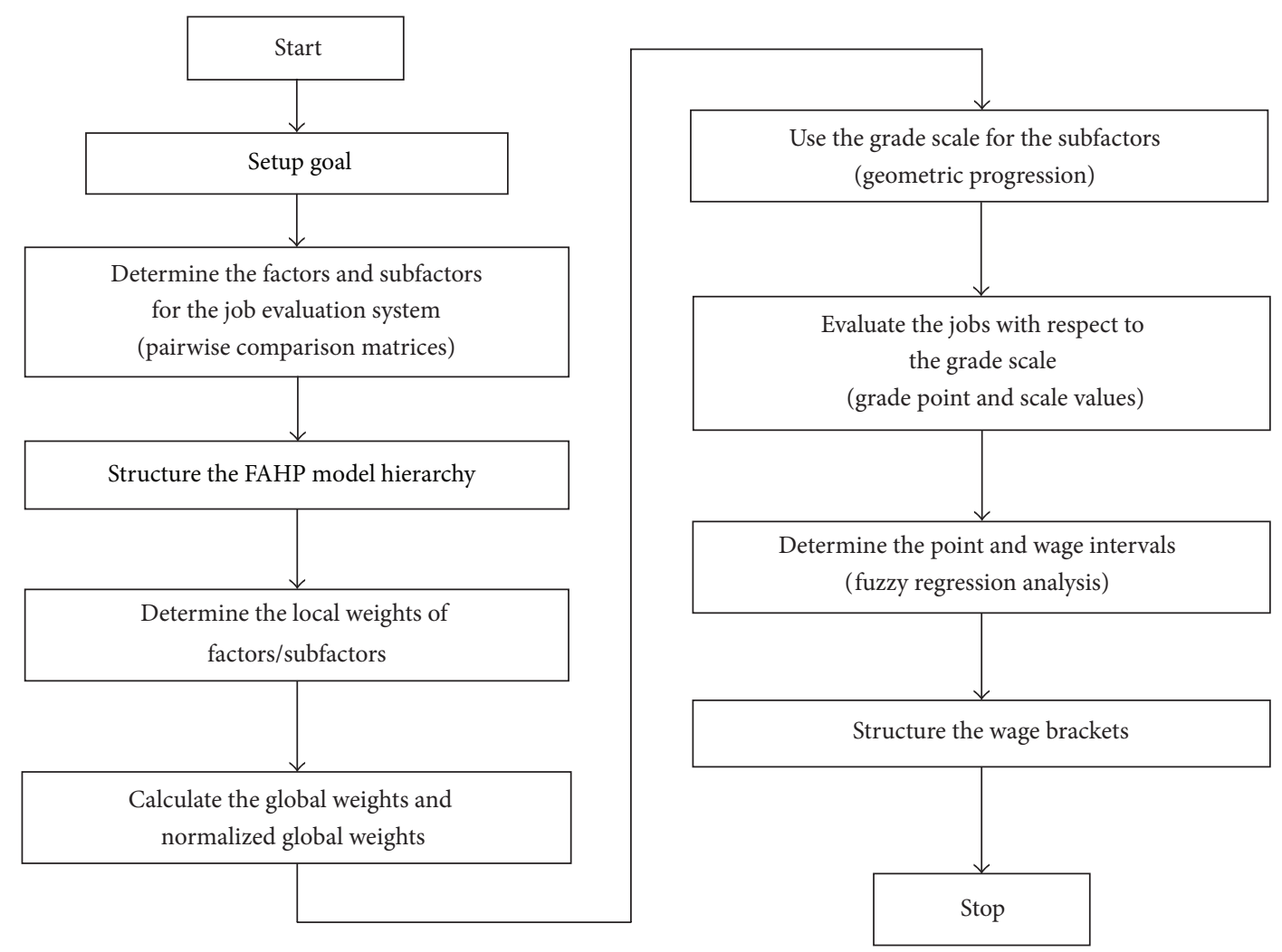

FIGURE 1: The steps of the algorithm of proposed job evaluation system.

In this regard, the proposed job evaluation system operating within a wider framework is tested on contributing factors in the evaluation studies.

Step 2 (structuring the FAHP model hierarchically (objective, factors, subfactors)). The FAHP model is composed of 3 stages. In the first stage, there is an objective of evaluating the jobs. There are the factors and the subfactors related to them in second and third stages, respectively. Then, the evaluation of the jobs with FRA and the structuring of the fuzzy wage brackets are involved in the fourth and the fifth stages. This hierarchy is shown in Figure 2.

Step 3 (determination of the local weights of the factors and subfactors by using fuzzy pairwise comparison matrices). The FAHP scale regarding relative importance to measure the relative weights of all the factors is given in Table 1.

In this step, local weights of the factors and subfactors which take part in the second and third levels of FAHP model, provided in Figure 2, are calculated. Pairwise comparison matrices are formed by the decision committee by using the scale given in Table 1 . These matrices are analyzed by Chang's extend analysis method and local weights are calculated as seen in examples of Table 2 for main factors and Table 3 for mastery subfactors.

Step 4 (calculating the global weights for the subfactors). Global weights of subfactors are calculated by multiplying the local weight of the sub-factor with the local weight of the
TABLE 1: The linguistic scale for determination of importance.

\begin{tabular}{lc}
\hline Linguistic scale for importance & Triangular fuzzy scale \\
\hline Equal importance (EI) & $(1,1,1)$ \\
Moderate importance (MI) & $(1,3,5)$ \\
Strong importance (SI) & $(3,5,7)$ \\
Very strong importance (VSI) & $(5,7,9)$ \\
Demonstrated importance (DI) & $(7,9,11)$ \\
\hline
\end{tabular}

factor which belongs to (Table 4). In order to evaluate according to total 1000 points, the global weights are normalized and given in the last column.

According to the weights given in Table 4, the factors of experience, predisposition, job risks, and working environment are in the foreground among the 13 subfactors, respectively.

Step 5 (graduation of the subfactors for point system). Utilizing the normalized global weights, the grades of the subfactors in Table 5 are calculated using geometric progression. The coefficient is used as 5 and progression multiplier is calculated as $\sqrt[n-1]{P_{\max } / P_{\min }}$, where $n=5$ and $P_{\max }$ and $P_{\min }$ are the maximum and the minimum points of jobs, respectively.

Step 6 (evaluation of the jobs by using the grade points of subfactors). The determined 86 jobs of steel company are evaluated using the grades obtained from Table 5 and the 


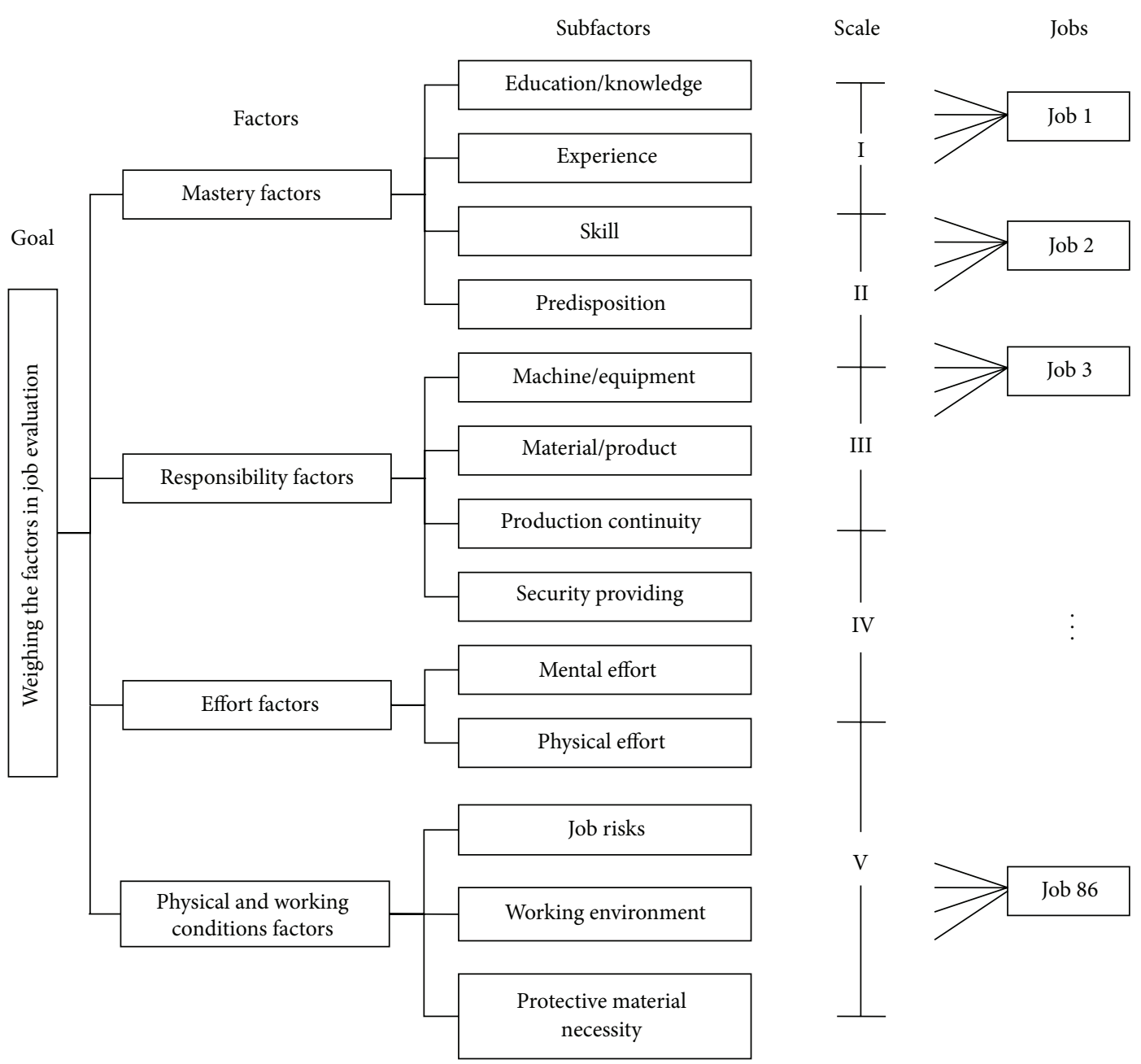

FIgURE 2: FAHP hierarchy for fuzzy job evaluation system.

scale values and the total points of each job are calculated and given in Table 6 thereafter.

Step 7 (determination of the point and wage intervals for the evaluated jobs using FRA). The total points are sequenced in ascending order; the minimum of them is 241 and the maximum is 592 . The range is divided into 5 intervals which have 5-point $\left(X_{1}, X_{2}, X_{3}, X_{4}, X_{5}\right)$ and 5-wage $\left(Y_{1}, Y_{2}, Y_{3}\right.$, $Y_{4}, Y_{5}$ ) variables for using in fuzzy linear regression analysis (FRA) taking into consideration the views of the decision committee and the features of the steel sector. The wage intervals of the jobs are decided with respect to the equivalent steel companies in the market which are 600-1000 for $X_{1}$, 1000-1500 for $X_{2}, 1500-2000$ for $X_{3}, 2000-3000$ for $X_{4}$, and $3000-5000$ for $X_{5}$.

The calculated fuzzy linear regression models obtained from the intervals for $h=0.1$ are given as follows, where $X_{0}=(1,1, \ldots, 1)^{T}$ :

$\widetilde{Y}_{1}=(-599.3443,-20.76899) X_{0}+(5.05964,0.2037769) X_{1}$,

$\widetilde{Y}_{2}=(-1432.457,-139.1500) X_{0}+(7.688034,0.5175689) X_{2}$,

$$
\begin{gathered}
\tilde{Y}_{3}=(-1060.654,23.63248) X_{0}+(6.75,0.02136752) X_{3}, \\
\widetilde{Y}_{4}=(-3749.089,643.2341) X_{0}+(12.98214,-1.130952) X_{4}, \\
\widetilde{Y}_{5}=(-11769.60,-94.34264) X_{0}+(28.05211,0.5567617) X_{5} .
\end{gathered}
$$

Accordingly, the fuzzy regressions for the levels of $h=0.5$ and $h=0.9$ are calculated as well. Utilizing the estimated fuzzy regression models, the upper and lower bounds are given in Table 7 for three different $h$-levels. As an example, the dispersions (the center, the lower, and the upper values) are diagrammatically demonstrated for the first interval in Figure 3.

When Figure 3 is analyzed, it is evident that the minimum dispersion is at level $h=0.1$ and increases towards $h=0.9$. Therefore, the managers of the steel companies are given options to determine which plan is convenient for their waging policies.

Step 8 (structuring the fuzzy wage brackets). Using the proposed fuzzy model, it is seen that the range interval of job points are formed between 241 and 592. Then, determined 86 
TABLE 2: Local weights and pairwise comparison matrix of main factors.

\begin{tabular}{lccccc}
\hline Main factors & MF & RF & WF & PF & Local weights \\
\hline MF & $(1,1,1)$ & $(1,3,5)$ & $(3,5,7)$ & $(1,3,5)$ & 0.423 \\
RF & $(1 / 5,1 / 3,1)$ & $(1,1,1)$ & $(1,3,5)$ & $(1,1,1)$ & 0.255 \\
WF & $(1 / 7,1 / 5,1 / 3)$ & $(1 / 5,1 / 3,1)$ & $(1,1,1)$ & $(1 / 5,1 / 3,1)$ & 0.067 \\
PF & $(1 / 5,1 / 3,1)$ & $(1,1,1)$ & $(1,3,5)$ & $(1,1,1)$ & 0.255 \\
\hline
\end{tabular}

TABLE 3: Weights and pairwise comparison matrix of mastery subfactors.

\begin{tabular}{lccccc}
\hline Mastery factors & EK & EX & SK & PD & Local weights \\
\hline EK & $(1,1,1)$ & $(1 / 7,1 / 5,1 / 3)$ & $(1,3,5)$ & $(1 / 5,1 / 3,1)$ & 0.207 \\
EX & $(3,5,7)$ & $(1,1,1)$ & $(3,5,7)$ & $(1,3,5)$ & 0.444 \\
SK & $(1 / 5,1 / 3,1)$ & $(1 / 7,1 / 5,1 / 3)$ & $(1,1,1)$ & $(1 / 5,1 / 3,1)$ & 0.032 \\
PD & $(1,3,5)$ & $(1 / 5,1 / 3,1)$ & $(1,3,5)$ & $(1,1,1)$ & 0.318 \\
\hline
\end{tabular}

TABLE 4: Calculated global weights of subfactors.

\begin{tabular}{|c|c|c|c|c|}
\hline Main factors and local weights & Subfactors & Local weights & Global weights & Global weights (normalized) \\
\hline \multirow{4}{*}{ Mastery factors (MF) (0.423) } & EK & 0.207 & 0.088 & 88 \\
\hline & EX & 0.444 & 0.188 & 188 \\
\hline & SK & 0.032 & 0.014 & 14 \\
\hline & $\mathrm{PD}$ & 0.318 & 0.135 & 135 \\
\hline \multirow{4}{*}{ Responsibility factors (RF) (0.255) } & MR & 0.150 & 0.038 & 38 \\
\hline & PR & 0.150 & 0.038 & 38 \\
\hline & $\mathrm{CR}$ & 0.350 & 0.089 & 89 \\
\hline & SR & 0.350 & 0.089 & 89 \\
\hline \multirow{2}{*}{ Workload factors (WF) (0.067) } & $\mathrm{ME}$ & 0.300 & 0.020 & 20 \\
\hline & $\mathrm{PE}$ & 0.700 & 0.047 & 47 \\
\hline \multirow{3}{*}{$\begin{array}{l}\text { Physical and working conditions } \\
\text { factors (PF) (0.255) }\end{array}$} & JR & 0.409 & 0.104 & 104 \\
\hline & WE & 0.409 & 0.104 & 104 \\
\hline & $\mathrm{PN}$ & 0.182 & 0.046 & 46 \\
\hline \multicolumn{3}{|c|}{ Total } & 1.00 & 1000 \\
\hline
\end{tabular}

TABLE 5: Graduation of subfactors.

\begin{tabular}{|c|c|c|c|c|c|}
\hline \multirow{2}{*}{ Subfactors } & \multicolumn{5}{|c|}{ Grade points } \\
\hline & $\mathrm{I}$ & II & III & IV & $\mathrm{V}$ \\
\hline EK & 18 & 26 & 39 & 59 & 88 \\
\hline $\mathrm{EX}$ & 38 & 56 & 84 & 126 & 188 \\
\hline SK & 3 & 4 & 6 & 9 & 14 \\
\hline $\mathrm{PD}$ & 27 & 40 & 60 & 90 & 135 \\
\hline MR & 8 & 11 & 17 & 25 & 38 \\
\hline $\mathrm{PR}$ & 8 & 11 & 17 & 25 & 38 \\
\hline $\mathrm{CR}$ & 18 & 27 & 40 & 60 & 89 \\
\hline SR & 18 & 27 & 40 & 60 & 89 \\
\hline $\mathrm{ME}$ & 4 & 6 & 9 & 13 & 20 \\
\hline $\mathrm{PE}$ & 9 & 14 & 21 & 31 & 47 \\
\hline $\mathrm{JR}$ & 21 & 31 & 47 & 70 & 104 \\
\hline WE & 21 & 31 & 47 & 70 & 104 \\
\hline $\mathrm{PN}$ & 9 & 14 & 21 & 31 & 46 \\
\hline
\end{tabular}


TABLE 6: Evaluation of 86 different jobs with scale values.

\begin{tabular}{|c|c|c|c|c|c|c|}
\hline \multirow{2}{*}{ Subfactors } & \multicolumn{2}{|c|}{ Job 1} & \multicolumn{2}{|c|}{ Job ... } & \multicolumn{2}{|c|}{ Job 86} \\
\hline & Scale & Points & Scale & Points & Scale & Points \\
\hline EK & IV & 59 & $\ldots$ & $\ldots$ & II & 26 \\
\hline EX & IV & 56 & $\ldots$ & $\ldots$ & II & 56 \\
\hline SK & II & 4 & $\ldots$ & $\ldots$ & II & 4 \\
\hline PD & II & 40 & $\ldots$ & $\ldots$ & I & 27 \\
\hline MR & IV & 25 & $\ldots$ & $\ldots$ & I & 8 \\
\hline PR & IV & 25 & $\ldots$ & $\ldots$ & I & 8 \\
\hline CR & IV & 60 & $\ldots$ & $\ldots$ & I & 18 \\
\hline SR & $\mathrm{V}$ & 89 & $\ldots$ & $\ldots$ & I & 18 \\
\hline $\mathrm{ME}$ & $\mathrm{V}$ & 20 & $\ldots$ & $\ldots$ & II & 6 \\
\hline $\mathrm{PE}$ & III & 21 & $\ldots$ & $\ldots$ & I & 9 \\
\hline$J R$ & IV & 70 & $\ldots$ & $\ldots$ & I & 21 \\
\hline WE & III & 47 & $\ldots$ & $\ldots$ & II & 31 \\
\hline $\mathrm{PN}$ & IV & 31 & $\ldots$ & $\ldots$ & $\mathrm{I}$ & 9 \\
\hline Total points & - & 547 & - & $\ldots$ & - & 241 \\
\hline
\end{tabular}

TABLE 7: Upper and lower bounds for $h$-levels $(h=0.1, h=0.5$, and $h=0.9)$.

\begin{tabular}{|c|c|c|c|c|c|c|}
\hline \multirow{2}{*}{\multicolumn{2}{|c|}{$h$-level }} & \multicolumn{5}{|c|}{ Point intervals } \\
\hline & & \multirow{2}{*}{$\begin{array}{c}241-310 \\
579\end{array}$} & \multirow{2}{*}{$\frac{311-380}{987}$} & \multirow{2}{*}{$\frac{381-450}{1486}$} & \multirow{2}{*}{$\begin{array}{c}451-520 \\
1987\end{array}$} & \multirow{2}{*}{$\frac{521-592}{2980}$} \\
\hline$h-01$ & $\mathrm{~L}$ & & & & & \\
\hline$n=0.1$ & $\mathrm{U}$ & 990 & 1505 & 2003 & 3033 & 5073 \\
\hline \multirow{2}{*}{$h=0.5$} & $\mathrm{~L}$ & 567 & 967 & 1461 & 1881 & 2818 \\
\hline & $\mathrm{U}$ & 1038 & 1549 & 2030 & 3079 & 5261 \\
\hline \multirow{2}{*}{$h=0.9$} & $\mathrm{~L}$ & 363 & 783 & 1232 & 930 & 1360 \\
\hline & $\mathrm{U}$ & 1342 & 1945 & 2269 & 3492 & 6955 \\
\hline
\end{tabular}

jobs are evaluated in respect to FRA and the wage groups are determined on the basis of both the total points and wages which are shown in Figure 4. Additionally, the acceptable wage scales and the wage management policies in similar companies are taken into account in the evaluation system. In the FRA, instead of crisp wages, fuzzy mathematical estimation model is run to estimate the upper and lower bounds of wages in the brackets. In the conventional system, the managers accepted that the upper bound is over $10 \%$ and the lower bound is below $10 \%$ of the estimated average values. The FRA-based wage brackets model is offered to the managers for an appropriate wage management system.

In the adaptation process to the new evaluation system, some jobs will be stated as overpaid (point A), some of them stated as underpaid (point B) or some which can remain at the same level (point C), as seen in Figure 4. Jobs A and B need to move to the desired level in the direction of their points. Job A can remain stable whenever the bracket reaches this wage level and job B can be paid more to reach the desired interval, conversely. In this manner, conversion can be performed. Here, there is no reason to reconcile with job $\mathrm{C}$ since the job is in the desired level. However, the adaptation process could be different when considering the $h$-levels (Table 8).

\section{Discussion and Conclusion}

At present, decisions are made within increasingly complex environments and structures, especially in steel industry. In most cases the use of experts' view is quite necessary and the different measurement systems need to be taken into account. In many of those decision-making processes the theory of fuzzy decision-making can easily be performed. Using the fuzzy group decision-making can overcome the difficulty of complex environments and systems. In general, many concepts, tools, and techniques can be used to improve human consistency and implementation of the complex models. These decision tools significantly contribute to more accurate decision-making.

In the job evaluation, the available information required for proficient decision-making is vague and uncertain in most cases. It is very difficult to obtain an exact or precise assessment data, for example, in description of the jobs and in construction of the payment system. To address this concern, the concepts of fuzzy numbers can be used to evaluate the determined factors. In this study, the job evaluation process is built as a multicriteria decision-making problem under the fuzzy environment, where the imprecise decision-maker's judgments are represented as triangular fuzzy numbers. 
TABLE 8: Adaptation process of related jobs.

\begin{tabular}{|c|c|c|c|c|c|c|}
\hline \multirow{2}{*}{ Jobs } & \multirow{2}{*}{ Points } & \multirow{2}{*}{ Wages } & \multirow{2}{*}{ Status } & \multicolumn{3}{|c|}{ Desired wage levels } \\
\hline & & & & $h=0.1$ & $h=0.5$ & $h=0.9$ \\
\hline A & 350 & 2150 & Overpaid & $987-1505$ & $967-1549$ & $783-1945$ \\
\hline B & 410 & 910 & Underpaid & $1486-2003$ & $1461-2030$ & $1232-2269$ \\
\hline $\mathrm{C}$ & 485 & 2450 & Desired & $1987-3033$ & $1881-3079$ & $930-3492$ \\
\hline
\end{tabular}

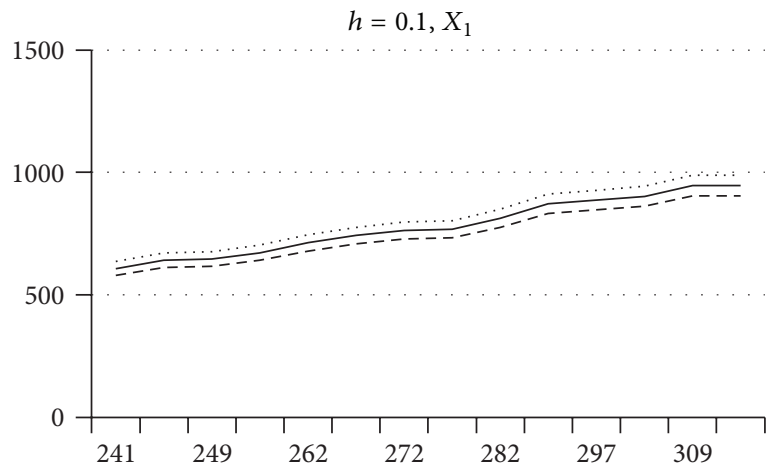

(a)

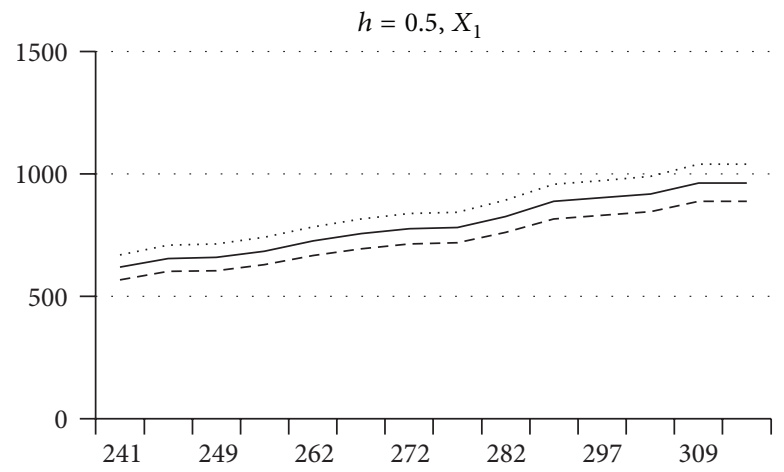

(b)

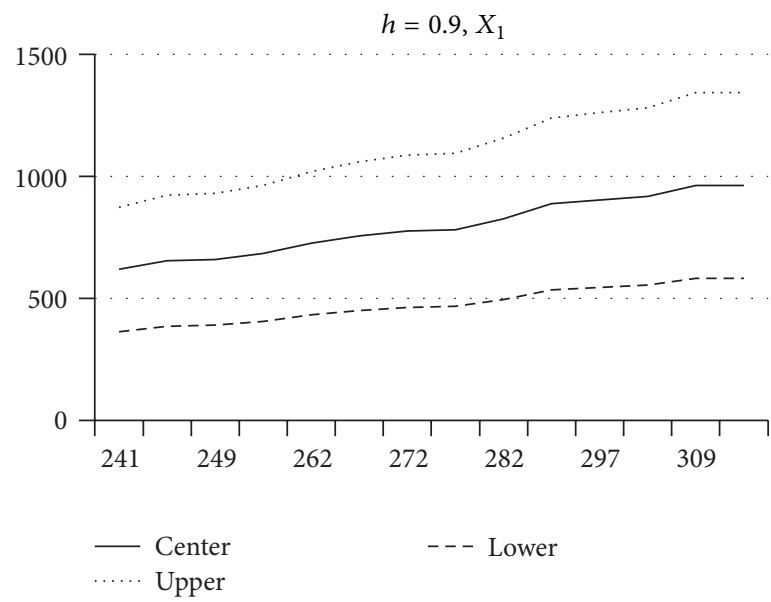

(c)

Figure 3: Dispersions of the first interval $\left(X_{1}\right)$ for (a) $h=0.1$, (b) $h=0.5$, and (c) $h=0.9$.

The FAHP method is used for the assessment of weights, and the points of each job are calculated afterwards. To improve the model, FRA-based wage brackets are considered and embedded into these processes by calculating the result of mathematical model which sets the upper and lower bounds. With such an approach, the subjectiveness of the committee is reduced and the most appropriate model for the steel companies according to their membership degrees is formed. The experimental study in the steel company shows the advantages and the usability of the proposed model. It distinguishes the jobs with a sensitive manner and determines the wage brackets as well.

Chang's FAHP method and its defuzzification process are used in this study. The fuzzy decision matrix is used at the beginning of FAHP method. Crisp weights are given to this method in order to be used as the coefficients of the objective function in the model. Although the inputs are given crisp, the outputs of upper and lower bounds of the brackets are obtained in fuzzy variables. Therefore, by using FLRA method, there is no longer need to use the statistical regression and its strict assumptions and prerequisites.

This model offers a valuable support for the steel industry in the decision-making and this approach can be applied to any company using the company's necessities in determining the factors and job variety. On the basis of the calculated job points, 5 different wage groups are constituted between the lower wage bound of TRY600 and upper wage bound of TRY5000. The payment structure is constituted for each worker in respect of the seniority in the brackets. Using the total points, the job groups are structured by the FRA. The FRA-based wage brackets model provides the ability to the managers to structure a flexible wage management system. 


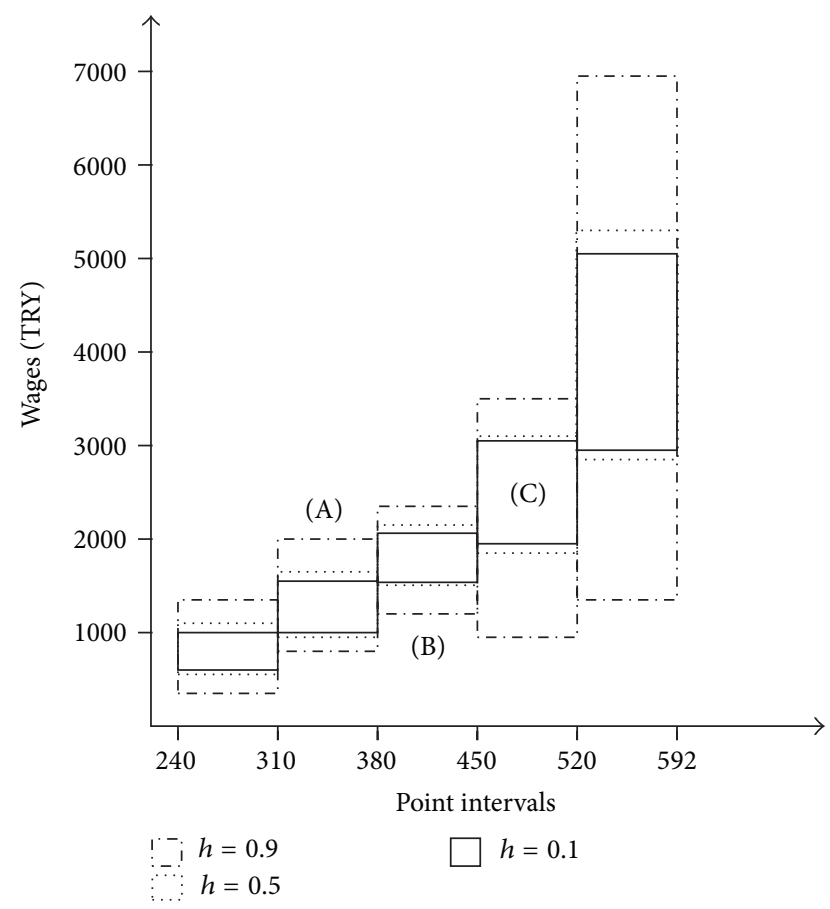

FIGURE 4: The calculated fuzzy wage brackets for 86 jobs.

Furthermore, the enhanced structural adjustment process to the new system is obtained. In this way, a new payment management system would be beneficial to the sectors where it can be applicable.

As an extension to this study, bearing in mind the relationships between the factors and subfactors in each level, one may consider the Analytical Network Process (ANP), which is a recently proposed method. Another extension is to reversion of the fuzzy scale from triangular to trapezoidal numbers, which - to the best of our knowledge-has not been applied to this kind of study so far. It is believed that both of the methods (FAHP and FRA) could be easily used to obtain more accurate results in the job evaluation and payment systems.

\section{Appendix}

The steps of Chang's [19-27] extent analysis approach are as follows: let $X=\left\{x_{1}, x_{2}, \ldots, x_{n}\right\}$ be an object set and let $U=\left\{u_{1}, u_{2}, \ldots, u_{m}\right\}$ be a goal set. According to the method of [27] extent analysis, each object is taken and extent analysis for each goal, $g_{i}$, is performed, respectively. Therefore, $m$ extent analysis values for each object can be obtained, with the following signs:

$$
M_{g_{i}}^{1}, M_{g_{i}}^{2}, \ldots, M_{g_{i}}^{m}, \quad i=1,2, \ldots, n,
$$

where all the $M_{g_{i}}^{j}(j=1,2, \ldots, m)$ are triangular fuzzy numbers.

The steps of Chang's extent analysis can be given as in the following.
Step 1. The value of fuzzy synthetic extent with respect to the $i$ th object is defined as

$$
S_{i}=\sum_{j=1}^{m} M_{g_{i}}^{j} \otimes\left[\sum_{i=1}^{n} \sum_{j=1}^{m} M_{g_{i}}^{j}\right]^{-1} .
$$

To obtain $\sum_{j=1}^{m} M_{g_{i}}^{j}$, perform the fuzzy addition operation of $\mathrm{m}$ extent analysis values for a particular matrix such that

$$
\sum_{j=1}^{m} M_{g_{i}}^{j}=\left(\sum_{j=1}^{m} l_{j}, \sum_{j=1}^{m} m_{j}, \sum_{j=1}^{m} u_{j}\right) .
$$

And to obtain $\left[\sum_{i=1}^{n} \sum_{j=1}^{m} M_{g_{i}}^{j}\right]^{-1}$, perform the fuzzy addition operation of $M_{g_{i}}^{j}(j=1,2, \ldots, m)$ values such that

$$
\sum_{i=1}^{n} \sum_{j=1}^{m} M_{g_{i}}^{j}=\left(\sum_{i=1}^{n} l_{i}, \sum_{i=1}^{n} m_{i}, \sum_{i=1}^{n} u_{i}\right),
$$

and then compute the inverse of the vector in (A.4) such that

$$
\left[\sum_{i=1}^{n} \sum_{j=1}^{m} M_{g_{i}}^{j}\right]^{-1}=\left(\frac{1}{\sum_{i=1}^{n} u_{i}}, \frac{1}{\sum_{i=1}^{n} m_{i}}, \frac{1}{\sum_{i=1}^{n} l_{i}}\right) .
$$

Step 2. The degree of possibility of $M_{2}=\left(l_{2}, m_{2}, u_{2}\right) \geq M_{1}=$ $\left(l_{1}, m_{1}, u_{1}\right)$ is defined as

$$
V\left(M_{2} \geq M_{1}\right)=\sup \left[\min \left(\mu_{M_{1}}(x), \mu_{M_{2}}(y)\right)\right]
$$

and can be equivalently expressed as follows:

$$
\begin{aligned}
V\left(M_{2} \geq M_{1}\right)= & \operatorname{hgt}\left(M_{1} \cap M_{2}\right)=\mu_{M_{2}}(d) \\
= & \begin{cases}1, & \text { if } m_{2} \geq m_{1}, \\
0, & \text { if } l_{1} \geq u_{2}, \\
\frac{l_{1}-u_{2}}{\left(m_{2}-u_{2}\right)-\left(m_{1}-l_{1}\right)}, & \text { otherwise, }\end{cases}
\end{aligned}
$$

where $d$ is the ordinate of the highest intersection point $D$ between $\mu_{M_{1}}$ and $\mu_{M_{2}}$. To compare $M_{1}$ and $M_{2}$, we need both the values of $V\left(M_{1} \geq M_{2}\right)$ and $V\left(M_{2} \geq M_{1}\right)$.

Step 3. The degree possibility for a convex fuzzy number to be greater than $k$ convex fuzzy numbers $M_{i}(i=1,2, \ldots, k)$ can be defined by

$$
\begin{aligned}
V & \left(M \geq M_{1}, M_{2}, \ldots, M_{k}\right) \\
& =V\left[\left(M \geq M_{1}\right),\left(M \geq M_{2}\right), \ldots,\left(M \geq M_{k}\right)\right] \\
& =\min V\left(M \geq M_{i}\right), \quad i=1,2, \ldots, k .
\end{aligned}
$$

Assume that

$$
d^{\prime}\left(B_{i}\right)=\min V\left(S_{i} \geq S_{k}\right) .
$$

For $k=1,2, \ldots, n ; k \neq i$. Then the weight vector is given by

$$
W^{\prime}=\left(d^{\prime}\left(B_{1}\right), d^{\prime}\left(B_{2}\right), \ldots, d^{\prime}\left(B_{n}\right)\right)^{T},
$$

where $B_{i}(i=1,2, \ldots, n)$ are $n$ elements. 
Step 4. Via normalization, the normalized weight vectors are

$$
W^{\prime}=\left(d\left(B_{1}\right), d\left(B_{2}\right), \ldots, d\left(B_{n}\right)\right)^{T},
$$

where $W$ is a nonfuzzy number.

\section{References}

[1] A. Spyridakos, Y. Siskos, D. Yannacopoulos, and A. Skouris, "Multicriteria job evaluation for large organizations," European Journal of Operational Research, vol. 130, pp. 375-387, 2009.

[2] M. Dağdeviren, D. Akay, and M. Kurt, "Analytical hierarchy process for job evaluation and application," Journal of the Faculty of Engineering and Architecture of Gazi University, vol. 19, pp. 131-138, 2004.

[3] E. Eraslan and B. Arıkan, "Determination of wages using the point method, seniority and success: an application in internal production department of a manufacturing facility," Journal of the Faculty of Engineering and Architecture of Gazi University, vol. 19, pp. 139-150, 2004.

[4] E. M. McCormick, Job Analysis: Methods and Application, AMACOM, New York, NY, USA, 1979.

[5] L. Xing, Y. Li, and L. Ma, "Study on the application of Point Method in Job Evaluation," in Proceedings of the 7th Wuhan International Conference on E-Business, vol. 1-3, pp. 2835-2839, 2008.

[6] D. Doverspike, A. M. Carlisi, G. V. Garrett, and R. A. Alexander, "Generalizability analysis of a point-method job evaluation instrument," Journal of Applied Psychology, vol. 68, pp. 476-483, 1983.

[7] B. Das and A. Garcia-Diaz, "Factor selection guidelines for job evaluation: a computerized statistical procedure," Computers \& Industrial Engineering, vol. 40, pp. 259-272, 2001.

[8] D. M. Figart, "Equal pay for equal work: the role of job evaluation in an evolving social norm," Journal of Economic Issues, vol. 34, pp. 1-19, 2000.

[9] B. N. Smith, P. G. Benson, and J. S. Hornsby, "The effects of job description content on job evaluation judgments," Journal of Applied Psychology, vol. 75, pp. 301-309, 1990.

[10] J. N. D. Gupta and N. U. Ahmed, "A goal programming approach to job evaluation," Computers \& Industrial Engineering, vol. 14, pp. 147-152, 1988.

[11] M. Dağdeviren, D. Akay, and M. Kurt, "Job evaluation, use of goal programming technique at determine factor degree points," Journal of the Faculty of Engineering and Architecture of Gazi University, vol. 19, pp. 89-95, 2004.

[12] M. Perc and A. Szolnoki, "Coevolutionary games-a mini review," BioSystems, vol. 99, pp. 109-125, 2010.

[13] M. Perc, J. Gomez-Gardenes, A. Szolnoki, L. M. Floria, and Y. Moreno, "Evolutionary dynamics of group interactions on structured populations-a review," Journal of the Royal Society Interface, vol. 10, no. 80, 2013.

[14] S. Gupta and M. Chakraborty, "Job evaluation in fuzzy environment," Fuzzy Sets and Systems, vol. 100, pp. 71-76, 1998.

[15] C. Kahraman, D. Ruan, and E. Tolga, "Capital budgeting techniques using discounted fuzzy versus probabilistic cash flows," Information Sciences, vol. 42, pp. 57-76, 2002.

[16] T. L. Saaty, The Analytic Hierarchy Process, McGraw-Hill, New York, NY, USA, 1980.

[17] P. J. M. Van Laarhoven and W. Pedrycz, "A fuzzy extension of Saaty's priority theory," Fuzzy Sets and Systems, vol. 11, no. 3, pp. 229-241, 1983.
[18] J. J. Buckley, "Fuzzy hierarchical analysis," Fuzzy Sets and Systems, vol. 17, no. 3, pp. 233-247, 1985.

[19] D. Y. Chang, "Applications of the extent analysis method on fuzzy AHP," European Journal of Operational Research, vol. 95, pp. 649-655, 1996.

[20] C. H. Cheng, "Evaluating naval tactical missile systems by fuzzy AHP based on the grade value of membership function," European Journal of Operational Research, vol. 96, pp. 343-350, 1997.

[21] C. Kahraman, Z. Ulukan, and E. Tolga, "A fuzzy weighted evaluation method using objective and subjective measures," in Proceedings of the International ICSC Symposium on Engineering of Intelligent Systems, vol. 1, pp. 57-63, 1998.

[22] C. Kahraman, D. Ruan, and I. Doğan, "Fuzzy group decisionmaking for facility location selection," Information Sciences, vol. 157, pp. 135-153, 2003.

[23] C. Kahraman, U. Cebeci, and D. Ruan, "Multi-attribute comparison of catering service companies using fuzzy AHP: the case of Turkey," International Journal Production Economics, vol. 87, pp. 171-184, 2004.

[24] G. Büyüközkan, T. Ertay, C. Kahraman, and D. Ruan, "Determining the importance weights for the design requirements in the house of quality using the fuzzy analytic network approach," International Journal of Intelligent Systems, vol. 19, pp. 443-461, 2004.

[25] E. Tolga, M. L. Demircan, and C. Kahraman, "Operating system selection using fuzzy replacement analysis and analytic hierarchy process," International Journal of Production Economics, vol. 97, pp. 89-117, 2005.

[26] O. Kulak and C. Kahraman, "Fuzzy multi-attribute selection among transportation companies using axiomatic design and analytic hierarchy process," Information Sciences, vol. 170, pp. 191-210, 2005.

[27] D. Y. Chang and L. L. Zhang, "Extent analysis and synthetic decision," in Optimization Techniques and Applications, vol. 1, pp. 352-359, World Scientific, Singapore, 1992.

[28] P. T. Chang, E. S. Lee, and S. A. Konz, "Applying fuzzy linear regression to VDT legibility," Fuzzy Sets and Systems, vol. 80, pp. 197-204, 1996.

[29] H. Tanaka, S. Uejima, and K. Asai, "Linear regression analysis with fuzzy model," IEEE Transactions of Systems Man Cybernet, vol. 12, pp. 903-907, 1982.

[30] P.-T. Chang and E. S. Lee, "A generalized fuzzy weighted leastsquares regression," Fuzzy Sets and Systems, vol. 82, no. 3, pp. 289-298, 1996.

[31] G. Peters, "Fuzzy linear regression with fuzzy intervals," Fuzzy Sets and Systems, vol. 63, no. 1, pp. 45-55, 1994.

[32] M. Sakawa and H. Yano, "Fuzzy linear regression analysis for fuzzy input-output data," Information Sciences, vol. 63, no. 3, pp. 191-206, 1992.

[33] B. Kim and R. R. Bishu, "Evaluation of fuzzy linear regression models by comparing membership functions," Fuzzy Sets and Systems, vol. 100, pp. 343-352, 1998.

[34] H. Tanaka and H. Lee, "Interval regression analysis by quadratic programming approach," IEEE Transaction on Fuzzy Systems, vol. 6, pp. 473-481, 1998.

[35] A. Azadeh, M. Khakestani, and M. Saberi, "A flexible fuzzy regression algorithm for forecasting oil consumption estimation," Energy Policy, vol. 37, pp. 5567-5579, 2009.

[36] F. M. Tseng and Y. C. Hu, "Quadratic-interval bass model for new product sales diffusion," Expert Systems with Applications, vol. 36, pp. 8496-8502, 2009. 
[37] Z. Sener and E. E. Karsak, "A combined fuzzy linear regression and fuzzy multiple objective programming approach for setting target levels in quality function deployment," Expert Systems with Applications, vol. 38, pp. 3015-3022, 2011.

[38] L. Bing, Z. Meilin, and X. Kai, "A practical engineering method for fuzzy reliability analysis of mechanical structures," Reliability Engineering \& System Safety, vol. 67, pp. 311-315, 2000.

[39] B. Heshmaty and A. Kandel, "Fuzzy linear regression and its application to forecasting in uncertain environment," Fuzzy Sets and Systems, vol. 15, pp. 159-191, 1985.

[40] Y. J. Lai and S. I. Chang, "A fuzzy approach for multi-response optimization: an off-line quality engineering problem," Fuzzy Sets and Systems, vol. 63, pp. 117-129, 1994.

[41] T. Y. Chou, G. S. Liang, and T. C. Han, "Application of fuzzy regression on air cargo forecast," Quality \& Quality, vol. 47, pp. 897-908, 2013.

[42] A. Azadeh, P. Sohrabi, and V. Ebrahimipour, "A fuzzy regression approach for improvement of gasoline consumption estimation with uncertain data," International Journal of Industrial Ad Systems Engineering, vol. 13, pp. 92-109, 2013.

[43] N. F. Pan, C. H. Ko, M. D. Yang, and K. C. Hsu, "Pavement performance prediction through fuzzy regression," Expert Systems with Applications, vol. 38, pp. 10010-10017, 2011.

[44] K. Chen, M. J. Rys, and E. S. Lee, "Modeling of thermal comfort in air conditioned rooms by fuzzy regression analysis," Mathematical and Computer Modelling, vol. 43, pp. 809-819, 2006.

[45] L. A. Zadeh, "The concept of a linguistic variable and its application to approximate reasoning. I," vol. 8, pp. 199-249, 1975.

[46] H. Lee and H. Tanaka, "Fuzzy regression analysis by quadratic programming reflecting central tendency," Behaviormetrika, vol. 25 , pp. 65-86, 1998. 


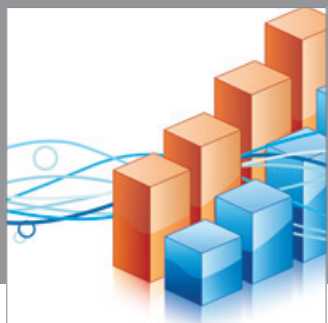

Advances in

Operations Research

mansans

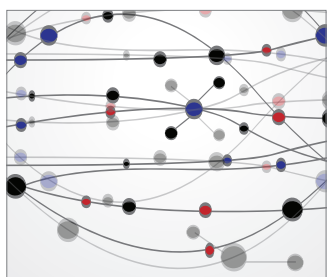

The Scientific World Journal
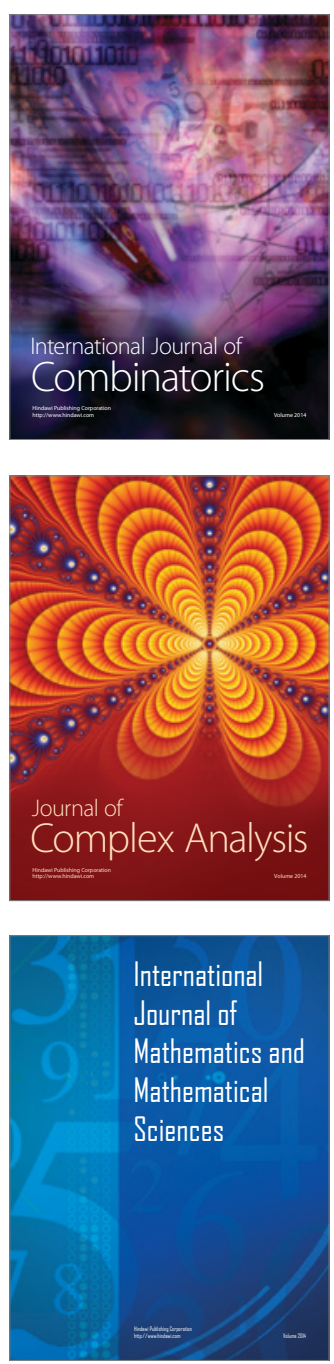
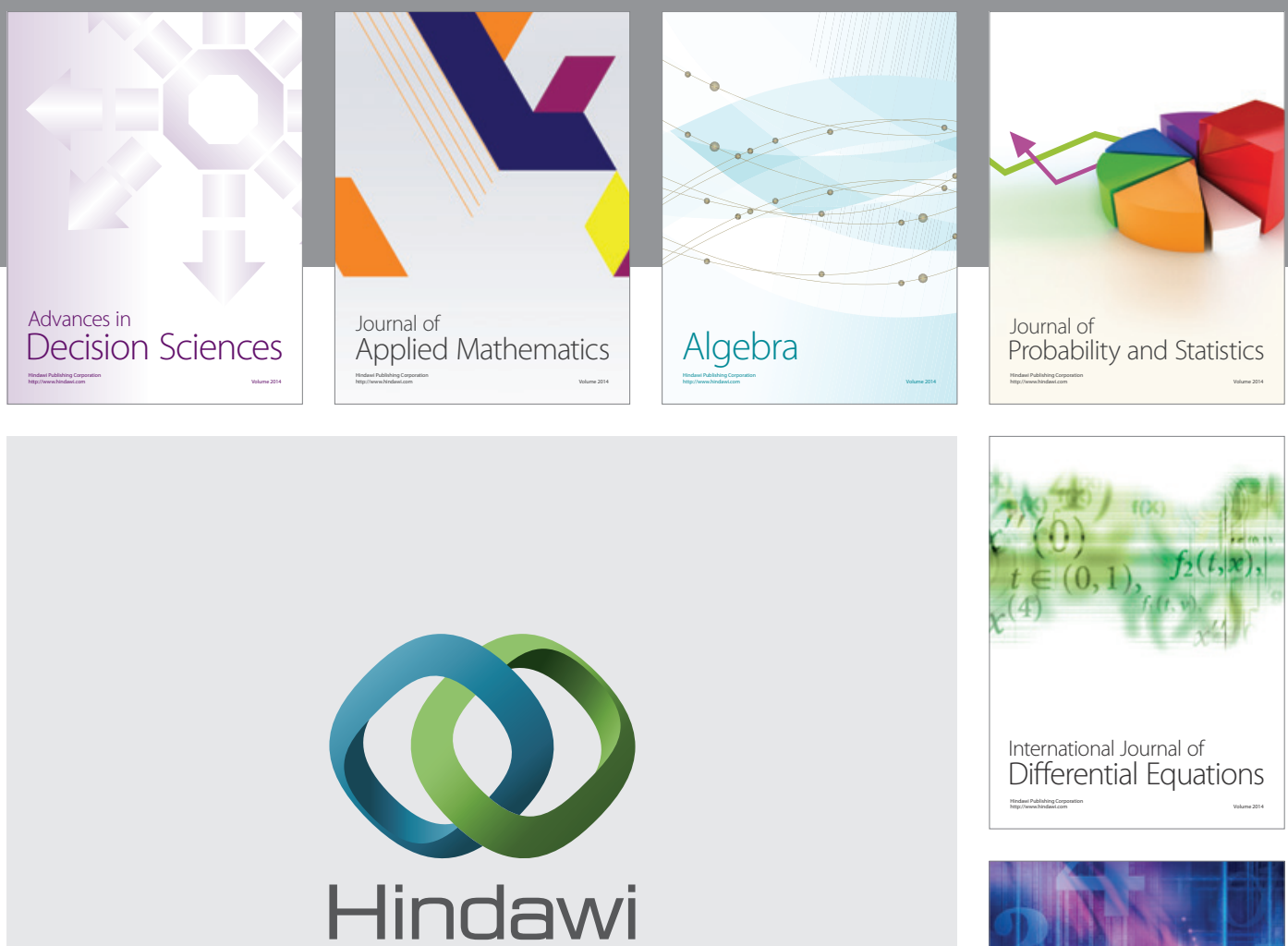

Submit your manuscripts at http://www.hindawi.com
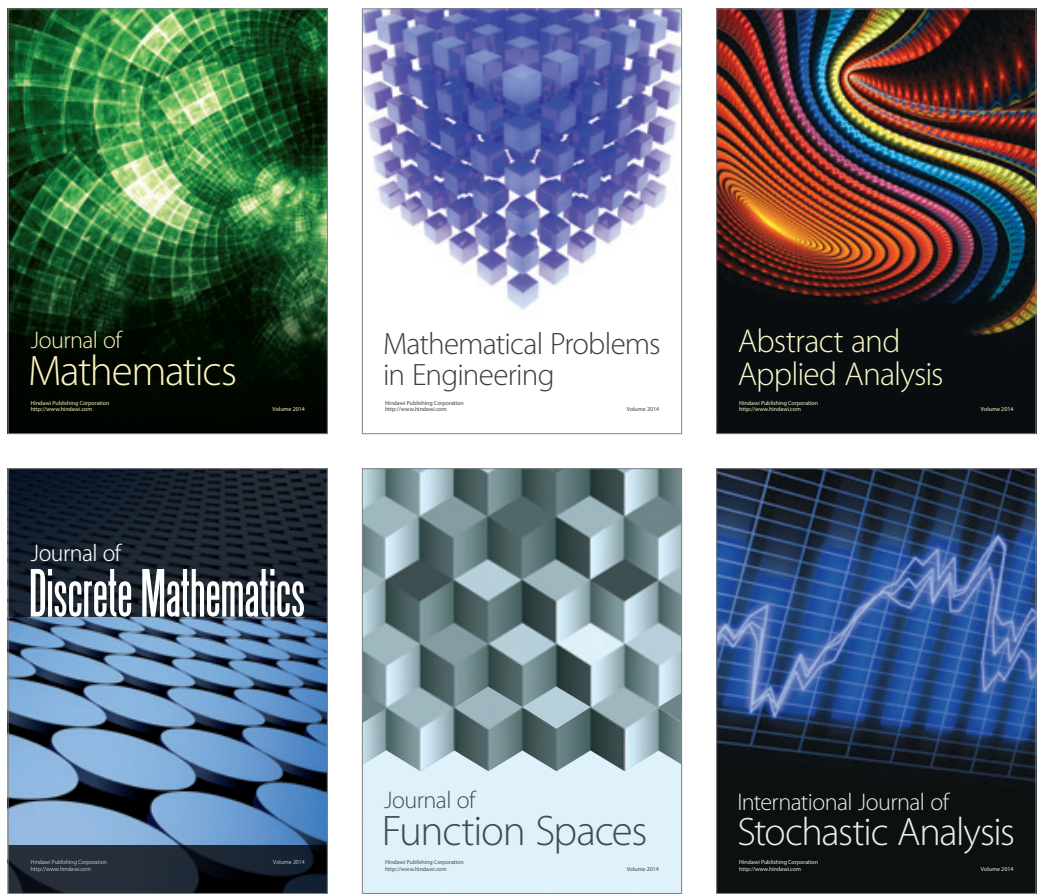

Journal of

Function Spaces

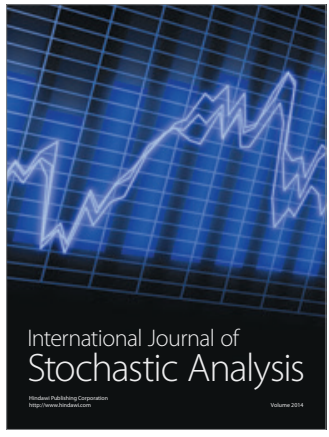

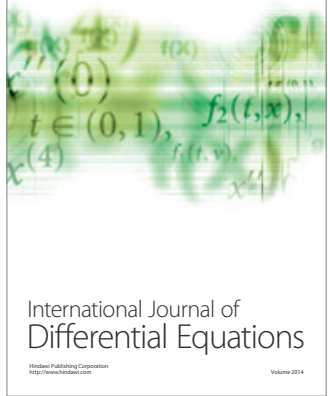
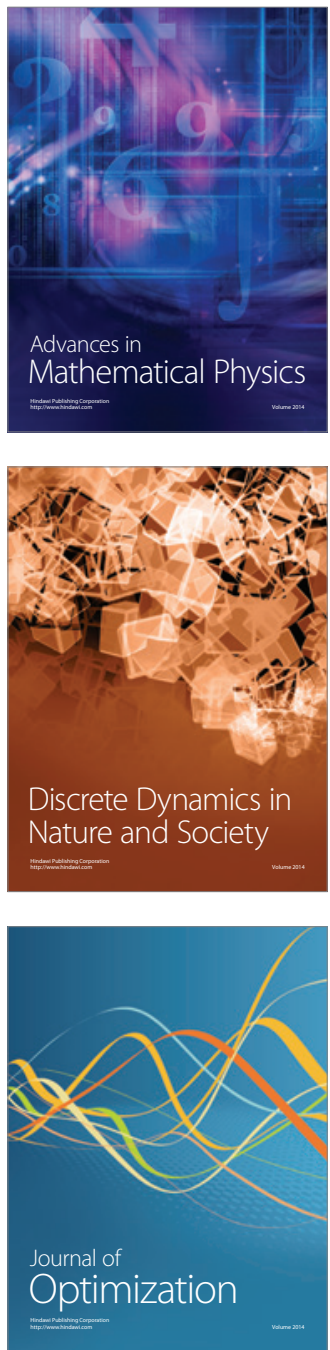